\title{
Normative Data of Macular Thickness and Retinal Nerve Fiber Layer Thickness (RNFL) With Axial Length and CCT by SLO OCT/Lenstar on Tribal People
}

\author{
Ferdinand Rapthap ${ }^{1 *}$, Monica Chaudhry ${ }^{1}$ and Valensha Surong ${ }^{2}$ \\ ${ }^{1}$ Department of Optometry and Vision science, Amity University, India \\ ${ }^{2}$ Mission Nethralaya, India
}

Submission: May 23, 2018; Published: June 27, 2018

*Corresponding author: Ferdinand Rapthap, Master of Clinical Optometry, Mawphlang Mawkohmon Meghalaya, Pin- 793121, India, Tel: +91 8575456703; Email: ferdinand2013rapthap@gmail.com

\section{Abstract}

Aim and Objectives: To study the relationship of Axial length, Central Corneal Thickness(CCT), Macular thickness and Retinal Nerve Fiber Layer thickness (RNFL) on the Tribal People of North East India by using of SLO OCT and Lenstar and to associate with the effects of Age, IOP and Refractive status on these Parameters.

Participants: 145 Individual of 290 eyes (93 females and 52 males)

Methods: Normal subject presenting to Mission Nethralaya Shillong were included in this study. The test was performed on both eyes of the same individual by a single examiner. All patient underwent clinical examination followed by study of macular thickness and RNFL thickness by spectral domain SLO OCT, and axial length with central corneal thickness by Lenstar. The data was collected and analysed based on IOP, age, gender and refractive status. Lastly, the data was compared with published literature of Indian and Caucasians population.

Results: The total number of patients enrolled in the study was 145 of 290 eyes. Number of male was 52 and Number of female was 93 with the age range from 15->55. The overall mean of macula Central Point Thickness (CPT) 164.96 \pm 30.88 Average macular Thickness (Avg Mac thick) $271.81 \pm 20.52$, Central sub field of macula (CSF) $191.01 \pm 32.33$ and for the Average RNFL thickness $107.61 \pm 13.45$ were as the Central Corneal thickness (CCT) $528.54 \pm 32.84$ and lastly the axial Length (AL) of $23.22 \pm 0.91$. Showed a strong positive correlation between the right and left eye of each individual $(r \geq 0.5, p<0.001)$. On further analysis of the RNFL, we found the Inferior (135.96) to be thickest followed superior (122.22), nasal (92.59) and temporal (80.99).

Gender wise shows no statistical significant difference for CPT, Avg mac thick, CSF, Avg RNFL thick, CCT and AL with (P= 0.33, 0.61, 0.97, 0.30 and 0.37 respectively). No age differences was noted in all the above parameters except in specific age group for axial length $\mathrm{P}=0.04$. Whereas CCT has a significant difference with IOP $(R=0.37, P=0.00)$.

Conclusion: This study was the first to provide a normative data for the Tribal people of North east India. The data obtain from this study finds to correlate well with the other published paper except Central point thickness of macular needs to look, as they appear to be thinner in compared to the rest.

Abbreviations: SLO-OCT: Scanning Laser Ophthalmoscopy; CCT: Central Corneal Thickness; AXL: Axial Length; RNFL: Retinal Nerve Fiber Layer; CPT: Central Point Thickness; CSF: Central Sub Field

\section{Rationale}

Many studies have been conducted comparing the axial length with macular thickness along with the RNFL. Maximum studies were conducted in Western/ Caucasian population and on Indian population. This particular study will be the first study to be conducted for the tribal people of North East India; main objective was to get the correlation of the parameters (Axial length, Macular thickness, RNFL thickness and Central corneal thickness with age, IOP and Refractive status. SD OCT with enhanced depth imaging was used for measuring the macular thickness and the RNFL LENSTAR for measuring the axial length.

a) The ethnicity of Mangoloid race specifically Khasi people.

b) Determine the Normative data of macular and RNFL thickness by used of SLO OCT 
c) Investigate the relationship of macular thickness, RNFL thickness, Axial length, Central Corneal thickness with Age, IOP and refractive status

d) Population based age group to be carried out in Meghalaya, which is a state of North East region of India.

e) Comparison of all the parameters with Indian population and Caucasians.

\section{Introduction}

The Khasis are one of the matrilineal tribes of Meghalaya in Northeast India. They have their own traditional religion (Niam Khasi), but about $65 \%$ converted into Christianity. They are Indio- Mongoloid Racial Stock, and speak Monkhmer language of the Austro- Asiatic group. The state of Meghalaya came into existences on April 2, 1970 attaining statehood on Jan 21, 1972. Meghalaya comprises of three tribes, the Garo, Khasis and Jaintias with the total population of 17,74779 and area of 22,429 sq. [1]. The maternal system gave to the women, the wife and mother, a social rather a personal standing.

Khasi people comparing from different regions have small but noted differences. Recent genetics researchers have shown that Khasis are closer to their Garo a neighbour state as compared to other population of Northeast India. It is describes as North- East Indian. Lastly, the variations remains high, with their features of flat nose and mouth, short people, high jaws and small and straighten black eyes.

Notation with proper assessment of Peripapillary Retinal Nerve Fiber layer (RNFL) by the OCT plays an important tool for the process and management of Diabetes, glaucoma and progression [2-4]. The RNFL is formed by the retinal Ganglion cells; it is found to be thickest near the optic nerve and gradually decreases towards the ora serrata. Macula is an oval yellowish area in the retina that surrounds the fovea and has the highest visual acuity due to the presence of cones Studies have shown the relationship between these two parameters by OCT $[5,6]$.

Axial length represents the distance from the anterior to the posterior poles of the eye. Which is the measurement from the anterior pole to the Bruch's membrane [7]. The average newborn eyeball is about $16 \mathrm{~mm}$ in diameter, in infant, the eye grows slightly of approximately $19 \mathrm{~mm}$. it gradually grow to the length of about $24-25 \mathrm{~mm}$.

Central Corneal thickness has its role of working the normal thickness is about $554+/-32.61$ microns one reason is that people with thin cornea (500 or less) are at a higher risk for glaucoma its mechanism is not entirely clear. Corneal thickness allows us to check the IOP (Goldman Tonometer). Thicker cornea has its pressure reading seems higher than it really is. IOP is important to determining the risk for glaucoma. Actual IOP may be underestimated in patients with thinner CCT and overestimated in patients with thicker CCT. Patients with thin cornea less $(555 \mu \mathrm{m})$ shows artificial low IOP readings, and with thicker cornea shows a higher reading of IOP than actually exists. The purpose of this study is to see the ethnicity of Mangoloid race specifically Khasi people to see the normative data of macular thickness with RNFL along the axial length and Central corneal thickness, and has any effects on age, refractive error, IOP and gender. Lastly, to see variation of these parameters in this region as with the other part of India and Caucasian population

\section{Methods}

Study Design: Observational, Cross sectional Study.

Subject Size: Patient collected 145 Individual of 290 eyes.

This study was conducted in Mission Nethralaya Shillong, Meghalaya.From January 1,2018 until April 2018 and the duration of the study is around 5 months. This was an observational, nonrandomized, prospective study and involved of 145 patients (290 eyes) normal individual. The patients were recruited from routine visits to the Hospital outpatient department. Informed consent was taken from the individual before inclusion. The study was approved by the ethics committee.

The subject that was included in this study involve patients with or without refractive error that is converted into spherical equivalent, along with the age group of 15 and above. Patient less that 15 was not included due to poor cooperation and unwillingness of the parents.

All subject after an informed consent was taken for the project, underwent complete ophthalmic examination which includes all the examination begins with the detailed history, Visual Acuity, extra ocular motility (EOM), refraction (subjective and objective), slit lamp bio microscopy, Intra ocular pressure with Non-contact Tonometer (NCT). After all the tests being completed the patients were taken for an investigation of the Axial length with Central Corneal Thickness (CCT) by the Lenstar LS 900, and for the posterior segment of the Macular thickness and the Retinal Nerve Fiber Layer thickness (RNFL) by the SD OCT SLO. These tests were conducted on both eyes of the same individual.

\section{Inclusion and exclusion criteria}

Inclusion criteria: Best corrected visual acuity of 6/6 with N6, Normal IOP range of $10-21 \mathrm{~mm} \mathrm{Hg}$, No history of any systemic diseases having ocular association, No history of any ocular diseases, and OCT signal strength of $\geq 6$ in each eye, Age group 15 to 80 years, Inform consent given and willingness of the patients

Exclusion criteria: Best corrected visual acuity worse than $6 / 9$ with N6, Intra ocular pressure (IOP) range $>21 \mathrm{mmHg}$, History of any ocular diseases, History of any systemic diseases having ocular associations, OCT signal strength $<6$ in each eye, Subjects $<15$ years of age 


\section{JOJ Ophthalmology}

\section{Optical Coherence Tomography}

Newly released SLO Optical Coherence Tomography (OTI, Toronto, Canada) was used, that has an increased axial resolution, faster scanning speeds and has been reported to have improved reproducibility but similar diagnostic accuracy in comparison with the earlier generation time domain OCT $[8,9]$. It was perform by a single clinician in order to avoid bias. It needs to have proper centration and signal strength of $>6$ and above. The main concentration to see was the Macular thickness and the RNFL thickness (Figure 1).

Figure 1: Macular Thickness Measurement.

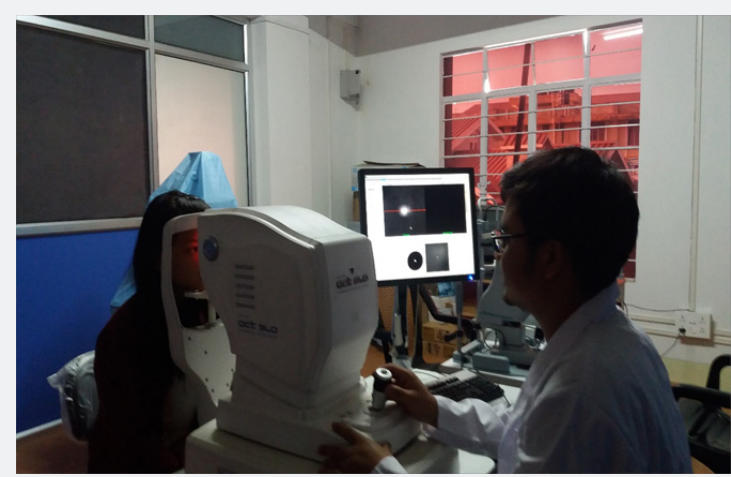

A single clinician was performed in order to avoid bias of the study. The scan was centred on the optic disc with a scanning diameter of $3.5 \mathrm{~mm}$ and $764 \mathrm{~A}$ scan were obtained. Automatic real time function to obtain multiple frames during scanning and optimize images by noise reduction. The RNFl was analysed based from fovea to disc technology. It gives the average thickness value for each clock hour and 4 quadrants as well as overall average thickness value for the whole circumference they were recorded in micrometres (Figure 2).

Figure 2: RNFL thickness measurement.
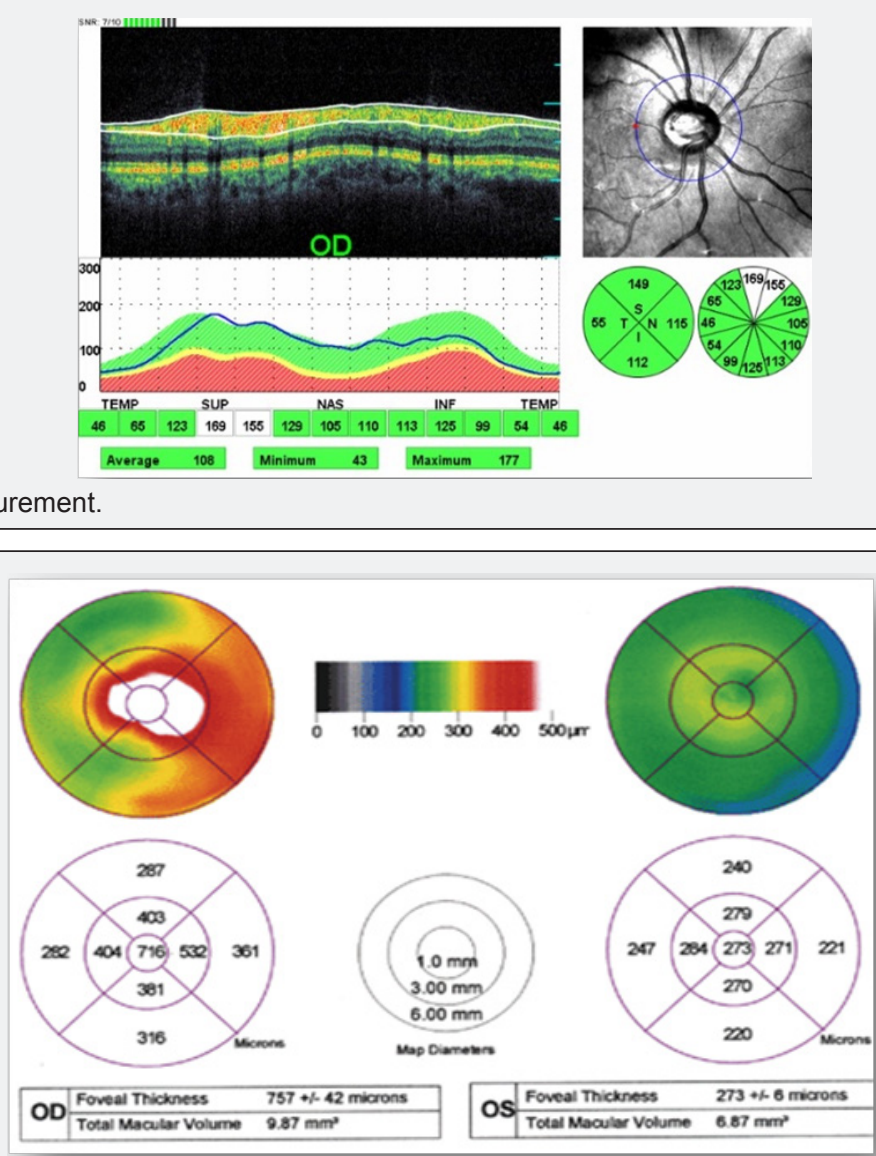

Figure 3: Macular thickness measurement using ETDRS subfield. 
For the macular thickness the spectralis OCT has an axial image resolution of $7 \mathrm{um}$, a lateral resolution of $14 \mathrm{um}$ and a scanning velocity up to 40,000 A scan per seconds. The Macular thickness was reported in a modified Early Treatment Diabetic Retinopathy study macular Map. Three parameters were recorded in this study. One the central sub field is $1 \mathrm{~mm}$ in diameter; second, the inner subfield is $3 \mathrm{~mm}$ in diameter and third is outer subfield, which is $6 \mathrm{~mm}$ in diameter. The retinal thickness in the inner and outer subfields, the central point thickness (CFT) the central point thickness (CPT) and the macular volume was calculated.

CPT was mainly targeted for the centred fovea, which is the average of 6 radial scan, whereas the CFT represents the central sub field of $1 \mathrm{~mm}$ in diameter as a whole (Figure 3).

\section{Lenstar}

The IOL master measurement Lenstar (Alcon Haag Lenstar Ls900 A-scan) is a non-invasive, non-contact OLCR (optical low coherence Reflectometry) biometry used for obtaining ocular measurements and performing calculation of appropriate power and type of IOL. The Lenstar LS 900 measures in this particular study were:

Axial Length: OLCR technology using super luminescent diode as the laser source allows the measurement of the axial length of the patient's eye, precisely on the patient's visual axis, in the presence of dense media. LENSTAR, A scan it is similar to an immersion ultrasound scan, for easy user interpretation.

Central Corneal thickness: like every other axial measurement with the Lenstar, optical coherence biometry is used to measure CCT with stunning reproducibility of \pm 2 um. CCT is a key parameter in glaucoma and surgery purposes like laser refractive surgery, myopic or hyperopic LASIK procedures, when there is no patient history (Figure 4).

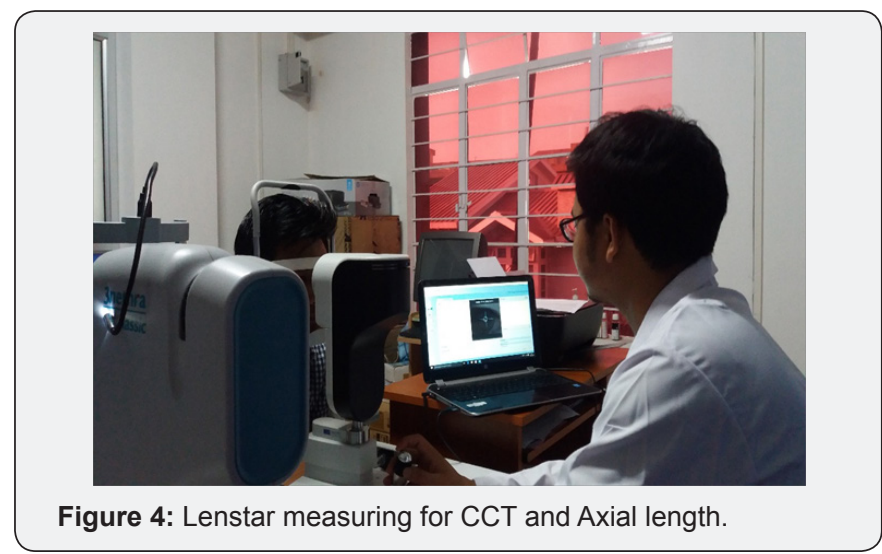

\section{Results}

Total number of normal patients who is willing to participate for this study was 145 (290 eyes). The number of male was 52 and the number of females 93 along with the age range from 15 to more than 80 as it was given in the Table 1 (Figures 5).

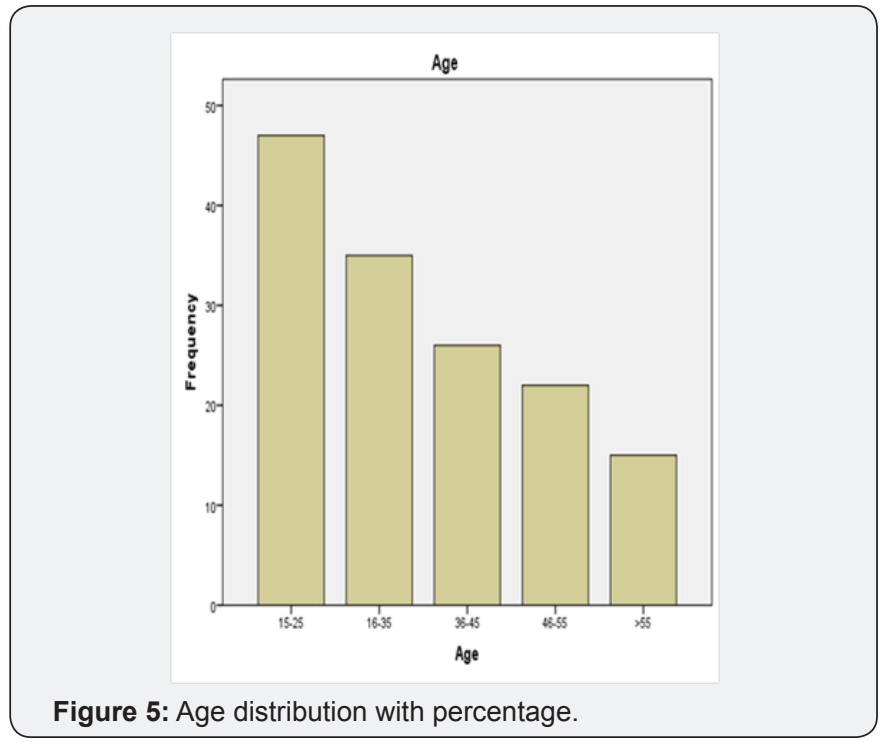

Table 1: Gender distribution with percentage.

\begin{tabular}{|c|c|c|c|c|c|}
\hline \multicolumn{2}{|c|}{ Gender } & Frequency & Percent & $\begin{array}{c}\text { Valid } \\
\text { Percent }\end{array}$ & $\begin{array}{c}\text { Cumulative } \\
\text { Percent }\end{array}$ \\
\hline Valid & Female & 93 & 64.1 & 64.1 & 64.1 \\
\hline & Male & 52 & 35.9 & 35.9 & 100.0 \\
\hline & Total & 145 & 100.0 & 100.0 & \\
\hline
\end{tabular}

The percentage of visitors were mostly young to adulthood and the minimum were the old age group (Table 2). Most patient that are willing to participate for this study were basically more of visual acuity of $6 / 6$ to $6 / 9$ and few are less than $6 / 60$ with a signal strength of not less than 7 in case of an OCT (Table 3) (Figure 6).

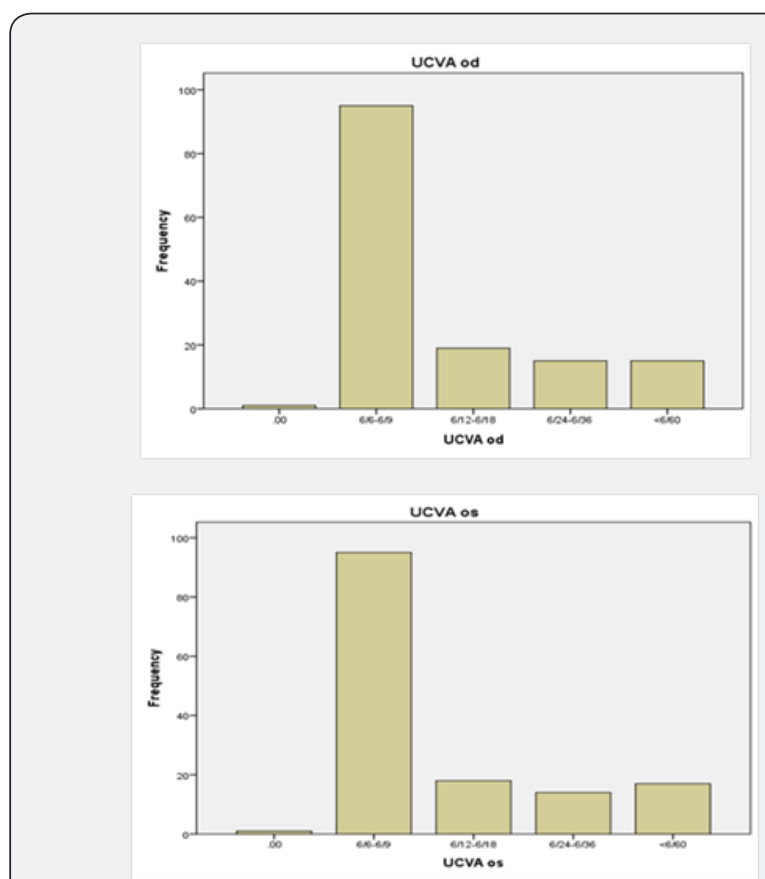

Figure 6: Patient UCVA in OD and OS. 
Table 2: Age distribution with percentage.

\begin{tabular}{|c|c|c|c|c|c|}
\hline \multicolumn{2}{|c|}{ Age } & Frequency & Percent & $\begin{array}{c}\text { Valid } \\
\text { Percent }\end{array}$ & $\begin{array}{c}\text { Cumulative } \\
\text { Percent }\end{array}$ \\
\hline Valid & $15-25$ & 47 & 32.4 & 32.4 & 32.4 \\
\hline & $16-35$ & 35 & 24.1 & 24.1 & 56.6 \\
\hline & $36-45$ & 26 & 17.9 & 17.9 & 74.5 \\
\hline & $46-55$ & 22 & 15.2 & 15.2 & 89.7 \\
\hline & $>55$ & 15 & 10.3 & 10.3 & 100.0 \\
\hline & Total & 145 & 100.0 & 100.0 & \\
\hline
\end{tabular}
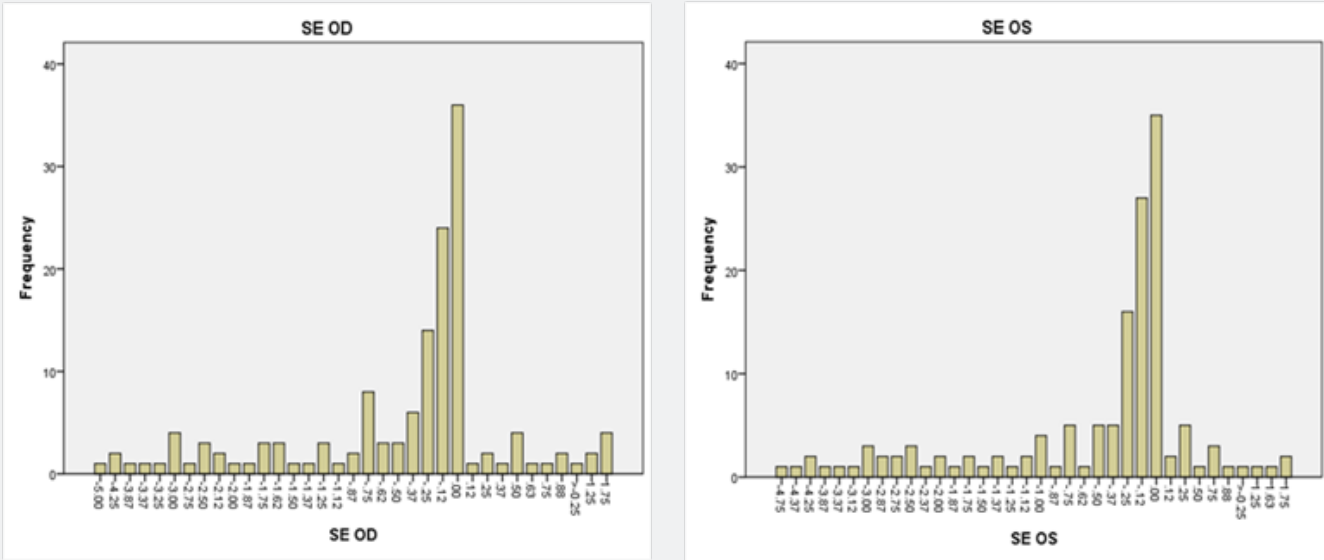

Figure 7: Graph presentation of the refractive status.

Table 4: Overall means values parameters required in the study.

\begin{tabular}{|c|c|c|c|}
\hline & Mean & Std. Deviation & N \\
\hline CPT mac od & 164.9586 & 30.88326 & 145 \\
\hline Avg mac od & 271.8069 & 20.51872 & 145 \\
\hline CSF mac OD & 191.0069 & 32.32678 & 145 \\
\hline Avg RNFL OD & 107.6138 & 13.45011 & 145 \\
\hline CCT od & 528.5448 & 32.83523 & 145 \\
\hline Axl od & 23.2170 & .91036 & 145 \\
\hline
\end{tabular}

The Figure 7 signifies the amount of refractive error patients participated for the study. The maximum amount of refractive error range from +0.25 to -0.25 considered as the highest peak
Table 3: Refractive status distribution.

\begin{tabular}{|c|c|c|c|}
\hline Refractive status & Emmetrope & Myope & Hyperope \\
\hline Frequency/ number & 61 & 66 & 18 \\
\hline
\end{tabular}

All refractive status was taken into consideration for least confusion by converting it into Spherical Equivalent, were Emmetrope was considered from +0.12 to -0.12 , Myope from -5.00 to -0.25 and lastly for Hyperope from +5.00 to +0.25 (Figure 7).

Table 5: Independent sample T test for male and female on the parameters.

\begin{tabular}{|c|c|c|c|c|c|c|}
\hline & Gender & $\mathbf{N}$ & Mean & Std. Deviation & Sig ( 2 tailed) & Std. Error Mean \\
\hline & Female & 93 & 163.0321 & 28.63021 & 0.33 & 2.96886 \\
\hline CPT mac od & Male & 53 & 168.4038 & 34.57432 & & 4.79443 \\
\hline \multirow[t]{2}{*}{ Avg mac od } & Female & 93 & 268.9892 & 18.73296 & & 1.94252 \\
\hline & Male & 52 & 276.8462 & 22.70129 & 0.61 & 3.14810 \\
\hline \multirow[t]{3}{*}{ Avg RNFL OD } & Female & 93 & 107.6559 & 13.35103 & & 1.38444 \\
\hline & Male & 52 & 107.5385 & 13.75623 & 0.94 & 1.90765 \\
\hline & Female & 93 & 186.7632 & 32.43716 & & 3.41542 \\
\hline CSF mac OD & Male & 53 & 198.5967 & 30.03479 & 0.97 & 4.16508 \\
\hline \multirow[t]{2}{*}{ CCT od } & Female & 93 & 528.6989 & 31.68177 & & 3.28525 \\
\hline & Male & 52 & 528.2692 & 35.12003 & 0.30 & 4.87027 \\
\hline
\end{tabular}

for Emmetrope, Myope with -5.00 DS and Hyperope +1.75 DS (Table 4).

The main Mean value of the parameters required in this study were following the ETDRS study of the macula and RNFL involve for macula Central Point Thickness $164.96 \pm 30.88$ Average macular Thickness $271.81 \pm 20.52$, Central sub field of macula $191.01 \pm 32.33$ and for the Average RNFL thickness $107.61 \pm$ 13.45 were as the Central Corneal thickness $528.54 \pm 32.84$ and lastly the axial Length of $23.22 \pm 0.91$. All the above parameters showed a strong positive correlation between the right and left eye of each individual $(r \geq 0.5, p<0.001)$. Therefore, data of right eyes was taken for further statistical analysis (Table 5). 


\section{JOJ Ophthalmology}

\begin{tabular}{|c|c|c|c|c|c|c|}
\hline IOP od & Female & 93 & 14.8817 & 2.68186 & .27810 \\
\hline & Male & 52 & 14.9423 & 2.86571 & 0.47 & .39740 \\
\hline Axl od & Female & 93 & 23.1030 & .83878 & .08698 \\
\hline
\end{tabular}

No significant differences was found between males and Central sub field, central corneal thickness (CCT), Intra ocular females in all the parameters by doing unpaired t- test of Central pressure (IOP) and Axial length with ( $p=0.33,0.61,0.94,0.97$, Point thickness, Avg macular thickness, Avg RNFL thickness, 0.30. 0.47 and 0.37 respectively) (Table 6).

Table 6: ANOVA between Parameters with Age group.

\begin{tabular}{|c|c|c|c|c|c|c|}
\hline ANOVA & & Sum of Squares & Df & Mean Square & $\mathbf{F}$ & Sig. \\
\hline \multirow{3}{*}{ Avg mac od } & Between Groups & 1839.389 & 4 & 459.847 & 1.095 & 0.361 \\
\hline & Within Groups & 58787.204 & 140 & 419.909 & & \\
\hline & Total & 60626.593 & 144 & & & \\
\hline \multirow[t]{3}{*}{ Avg RNFL OD } & Between Groups & 590.938 & 4 & 147.735 & 0.812 & 0.519 \\
\hline & Within Groups & 25459.434 & 140 & 181.853 & & \\
\hline & Total & 26050.372 & 144 & & & \\
\hline \multirow[t]{3}{*}{ CCT od } & Between Groups & 1380.845 & 4 & 345.211 & 0.314 & 0.868 \\
\hline & Within Groups & 153873.114 & 140 & 1099.094 & & \\
\hline & Total & 155253.959 & 144 & & & \\
\hline \multirow[t]{3}{*}{ Axl od } & Between Groups & 12.361 & 4 & 3.09 & 4.044 & 0.004 \\
\hline & Within Groups & 106.979 & 140 & 0.764 & & \\
\hline & Total & 119.34 & 144 & & & \\
\hline
\end{tabular}

The analysis of variance between parameters showed a Thickness with $(p=0.36,0.52$ and 0.87 respectively). Therefore, significant difference between Axial length and age groups ( $\mathrm{p}=$ 0.04). However, no variation with age was seen in the Average Post hoc Bonferroni correction was done for the axial length to Macular thickness, Average RNFL thickness, and Central Corneal find the specific variations between the age groups (Table 7).

Table 7: Post HOC Bonferroni test to see the significant difference between the age group.

\begin{tabular}{|c|c|c|c|c|c|c|c|}
\hline \multicolumn{8}{|c|}{ Bonferroni } \\
\hline \multirow{2}{*}{$\begin{array}{l}\text { Dependent } \\
\text { Variable }\end{array}$} & \multirow{2}{*}{ (I) Age } & \multirow{2}{*}{ (J) Age } & \multirow{2}{*}{$\begin{array}{c}\text { Mean } \\
\text { Difference (I-J) }\end{array}$} & \multirow{2}{*}{ Std. Error } & \multirow{2}{*}{ Sig. } & \multicolumn{2}{|c|}{ 95\% Confidence Interval } \\
\hline & & & & & & Lower Bound & Upper Bound \\
\hline & $15-25$ & 1 & 0.40879 & 0.19517 & 0.38 & -0.1479 & 0.9654 \\
\hline & & 2 & 0.53398 & 0.21365 & 0.136 & -0.0754 & 1.1434 \\
\hline & & 3 & $.67254^{*}$ & 0.22581 & 0.034 & 0.0285 & 1.3166 \\
\hline & & 4 & $.83070^{*}$ & 0.25923 & 0.017 & 0.0913 & 1.5701 \\
\hline & $26-35$ & 1 & -0.40879 & 0.19517 & 0.38 & -0.9654 & 0.1479 \\
\hline & & 2 & 0.12519 & 0.22632 & 1 & -0.5203 & 0.7707 \\
\hline & & 3 & 0.26375 & 0.23784 & 1 & -0.4146 & 0.9421 \\
\hline & & 4 & 0.4219 & 0.26977 & 1 & -0.3475 & 1.1913 \\
\hline & $36-45$ & 1 & -0.53398 & 0.21365 & 0.136 & -1.1434 & 0.0754 \\
\hline & & 2 & -0.12519 & 0.22632 & 1 & -0.7707 & 0.5203 \\
\hline & & 3 & 0.13857 & 0.25323 & 1 & -0.5837 & 0.8608 \\
\hline & & 4 & 0.29672 & 0.28343 & 1 & -0.5117 & 1.1051 \\
\hline & $46-55$ & 1 & $-.67254^{*}$ & 0.22581 & 0.034 & -1.3166 & -0.0285 \\
\hline & & 2 & -0.26375 & 0.23784 & 1 & -0.9421 & 0.4146 \\
\hline & & 3 & -0.13857 & 0.25323 & 1 & -0.8608 & 0.5837 \\
\hline & & 4 & 0.15815 & 0.2927 & 1 & -0.6767 & 0.993 \\
\hline & $>55$ & 1 & $-.83070^{*}$ & 0.25923 & 0.017 & -1.5701 & -0.0913 \\
\hline
\end{tabular}




\section{JOJ Ophthalmology}

\begin{tabular}{|l|l|l|l|l|l|l|l|}
\hline & & 2 & -0.4219 & 0.26977 & 1 & -1.1913 & 0.3475 \\
\hline & & 3 & -0.29672 & 0.28343 & 1 & -1.1051 & 0.5117 \\
\hline & & 4 & -0.15815 & 0.2927 & 1 & -0.993 & 0.6767 \\
\hline
\end{tabular}

*. The mean difference is significant at the 0.05 level.

Post HOC Bonferroni shows that the difference in only between groups 1 (15-25) with Group 3 and 4. In addition, Group 4 (46-55) with 1, lastly group 5 (>55) with Group 1 (Table 8). From the above correlation, it tells us about the relationship trend between the parameters with age Refractive status and IOP. From the given Table 8 we can draw a conclusion that Age has a positive correlation with significant difference to the spherical equivalent (SE), and a negative correlation to IOP and Axial length. Where SE has positive correlation to age and negative correlation to IOP and Axial length. IOP has negative correlation to age and SE and positive correlation to central corneal thickness (CCT) and Axial length. Lastly, Average macular thickness has positive correlation to Average RNFL (Table 9).

Table 8: Correlation between the parameters with age, refractive status and IOP.

\begin{tabular}{|c|c|c|c|c|c|c|c|c|}
\hline \multicolumn{2}{|r|}{ Correlations } & Age & SE OD & IOP od & Avg mac od & Avg RNFL OD & CCT od & Axl od \\
\hline \multirow{3}{*}{ Age } & Pearson Correlation & 1 & $.388^{* *}$ & $-.188^{*}$ & .055 & .008 & -.060 & $-.309 * *$ \\
\hline & Sig. (2-tailed) & & .000 & .024 & .515 & .919 & .471 & .000 \\
\hline & $\mathrm{N}$ & 145 & 145 & 145 & 145 & 145 & 145 & 145 \\
\hline \multirow{3}{*}{ SE OD } & Pearson Correlation & $.388^{* *}$ & 1 & -.160 & .061 & .145 & -.133 & $-.563^{* *}$ \\
\hline & Sig. (2-tailed) & .000 & & .055 & .465 & .082 & .109 & .000 \\
\hline & $\mathrm{N}$ & 145 & 145 & 145 & 145 & 145 & 145 & 145 \\
\hline \multirow{3}{*}{ IOP od } & Pearson Correlation & $-.188^{*}$ & -.160 & 1 & -.060 & -.015 & $.369 * *$ & $.176^{*}$ \\
\hline & Sig. (2-tailed) & .024 & .055 & & .472 & .862 & .000 & .034 \\
\hline & $\mathrm{N}$ & 145 & 145 & 145 & 145 & 145 & 145 & 145 \\
\hline \multirow{3}{*}{$\begin{array}{c}\text { Avg mac } \\
\text { od }\end{array}$} & Pearson Correlation & .055 & .061 & -.060 & 1 & $.449 * *$ & -.071 & -.135 \\
\hline & Sig. (2-tailed) & .515 & .465 & .472 & & .000 & .399 & .104 \\
\hline & $\mathrm{N}$ & 145 & 145 & 145 & 145 & 145 & 145 & 145 \\
\hline \multirow{3}{*}{$\begin{array}{c}\text { Avg } \\
\text { RNFL } \\
\text { OD }\end{array}$} & Pearson Correlation & .008 & .145 & -.015 & $.449^{* *}$ & 1 & .059 & -.157 \\
\hline & Sig. (2-tailed) & .919 & .082 & .862 & .000 & & .481 & .060 \\
\hline & $\mathrm{N}$ & 145 & 145 & 145 & 145 & 145 & 145 & 145 \\
\hline \multirow{3}{*}{ CCT od } & Pearson Correlation & -.060 & -.133 & $.369^{* *}$ & -.071 & .059 & 1 & .155 \\
\hline & Sig. (2-tailed) & .471 & .109 & .000 & .399 & .481 & & .062 \\
\hline & $\mathrm{N}$ & 145 & 145 & 145 & 145 & 145 & 145 & 145 \\
\hline \multirow{3}{*}{ Axl od } & Pearson Correlation & $-.309^{* *}$ & $-.563^{* *}$ & $.176^{*}$ & -.135 & -.157 & .155 & 1 \\
\hline & Sig. (2-tailed) & .000 & .000 & .034 & .104 & .060 & .062 & \\
\hline & $\mathrm{N}$ & 145 & 145 & 145 & 145 & 145 & 145 & 145 \\
\hline \multicolumn{9}{|c|}{ **. Correlation is significant at the 0.01 level (2-tailed). } \\
\hline \multicolumn{9}{|c|}{ *. Correlation is significant at the 0.05 level (2-tailed). } \\
\hline
\end{tabular}

Table 9: Normative Data of OCT parameters SLO OCT (ST).

\begin{tabular}{|c|c|c|c|c|c|}
\hline Parameters (OCT) & Total Number & Minimum & Maximum & Mean & Std. deviation \\
\hline CPT & 145 & 101 & 236 & 264 & 192.33 \\
\hline CSF & 145 & 102 & 323 & 278.42 & 27.57 \\
\hline Sup Inner & 145 & 166 & 312 & 265.89 & 23.99 \\
\hline Tem Inner & 145 & 158 & 330 & 278.95 & 26.03 \\
\hline Inf Inner & 145 & 142 & 329 & 267.95 & 28.59 \\
\hline Nas Inner & 145 & 107 & 343 & 274.95 & 28.35 \\
\hline Sup Outer & 145 & 62 & 307 & 255.11 & 20.49 \\
\hline Tem Outer & 145 & 143 & & & \\
\hline
\end{tabular}




\begin{tabular}{|c|c|c|c|c|c|}
\hline Nas Outer & 145 & 204 & 396 & 295.20 & 24.96 \\
\hline Total Avg & 145 & 198 & 379 & 271.80 & 20.51 \\
\hline Total Vol & 145 & 5.57 & 8.88 & 107.61 & 13.45 \\
\hline Avg Of RNFL & 145 & 68 & 134 & 122.22 & 19.32 \\
\hline Sup RNFL & 145 & 70 & 166 & 135.96 & 19.92 \\
\hline Inf RNFL & 145 & 78 & 195 & 92.59 & 18.92 \\
\hline Nas RNFL & 145 & 56 & 134 & 80.99 & 15.40 \\
\hline Tem RNFL & 145 & 68 & & 156 \\
\hline
\end{tabular}

The Full form of the above aberration (CPT: Central Point Thickness; CSF: Central Subfield; SI: Superior Inner, TI: Temporal Inner; II: Inferior Inner; NI: Nasal Inner; SO: Superior Outer; TO: Temporal Outer; IO: Inferior Outer; NO: Nasal Outer; Avg: Average; Vol: Volume; RNFL: Retinal Nerve Fiber Layer).

From the above table it give us the normative data mean value of each parameters, by using of SLO OCT. It is done on the tribal people of North East India on macular and RNFL thickness overall, by the Methods of ETDRS follows with the Minimum and maximum Range given on each parameters,

The Table 10 gives us the normative data of all the required parameters. Using of the same instrument but of different population size. The current study was compared with the Caucasians and Indian population as a whole. We found no significant differences between average macular thickness, average RNFL thickness, axial length and central corneal thickness. The only things needed to take into consideration is the macular central point thickness, which appears to be thinner as compared to Indian and Caucasians population.

Table 10: Normative mean of current study compared to others.

\begin{tabular}{|c|c|c|c|}
\hline Parameters & Current study & Caucasians & $\begin{array}{c}\text { Indian } \\
\text { population }\end{array}$ \\
\hline $\begin{array}{c}\text { Average } \\
\text { Macular } \\
\text { thickness }\end{array}$ & $271.81 \pm 20.52$ & $\begin{array}{c}262.8 \pm 13.34 \\
{[16]}\end{array}$ & $\begin{array}{c}279.43 \pm 7.18 \\
{[24]}\end{array}$ \\
\hline $\begin{array}{c}\text { Macular } \\
\text { Central point } \\
\text { thickness }\end{array}$ & $164.96 \pm 30.88$ & $\begin{array}{c}227.3+/-23.2 \\
{[16]}\end{array}$ & $\begin{array}{c}241.75 \pm 17.31 \\
{[24]}\end{array}$ \\
\hline $\begin{array}{c}\text { Average RNFL } \\
\text { thickness }\end{array}$ & $107.61 \pm 13.45$ & $\begin{array}{c}114.8 \pm 13.3 \mu \mathrm{m} \\
{[23]}\end{array}$ & $\begin{array}{c}112.56 \pm 5.19 \\
{[24]}\end{array}$ \\
\hline $\begin{array}{c}\text { Axial length } \\
\text { Central corneal } \\
\text { thickness }\end{array}$ & $23.22 \pm 0.91$ & $23.5 \pm 0.70[37]$ & $\begin{array}{c}22 \pm 0.81 \mathrm{~mm} \\
{[29]}\end{array}$ \\
\hline
\end{tabular}

\section{Discussion}

OCT has emerged as one of the most important tool in the field of eye care. It has emerged both qualitative and quantitative data regarding anterior and posterior segments of the eye [38]. OCT has increased the hope to obtain a more reliable tool in an attempt to define the changes in the Retina mainly by spectral Domain OCT $[6,8,9,11,12]$. Many studies has been done to compare Macular thickness with RNFL thickness with age and Gender [15] and also with diseases like glaucoma [2,6], diabetic retinopathy $[3,4]$.
This study gives us the normative data of macular thickness, RNFL thickness, and axial length in relationship with IOP, Central corneal thickness, Age, gender and refractive status. To our knowledge, the current report is the first to present the data from the normal population of the Scheduled Tribe people (North East state Of India) which mainly concentrated of the Meghalaya people.

Several studies has been conducted between macular thickness and RNFL thickness they found significant difference in them [20,39], similarly in this study we found there is a significant difference. The mean average of macular thickness was found to be $271.81 \pm 20 \mathrm{um}$, Average RNFL thickness 107.61 \pm 13 um, Mean CPT was $164.96 \pm 30$, mean CSF was $191.01 \pm 32.33$ and Total volume of macular was $7.62 \pm 0.51$ whereas Average RNFL thickness mean was $107.67 \pm 13.45$ with the Superior RNFL mean was $122.22 \pm 19.32$, Inferior RNFL mean was 135.96 \pm 19.92 , Nasal RNFL mean was 92.59 and Temporal RNFL mean was $80.99 \pm 15.40$ this present study showed maximum RNFL thickness in the inferior quadrant followed by superior, nasal, and temporal supporting the ISNT rule by Jonas et al. $[23,25,40]$.

In this study, the total number of participant was 145 (93 females and 52 males) with the age range from 15 to 80 and above. This study gives us the parameters OCT of macular and RNFL that follows the ETDRS study, show no significant differences between genders, age, and Refractive status (Emmetrope - 61, Myope - 66 and Hyperope - 18) [14,15,18].

However when looking at all the parameters of the of Axial length(mean value 23.22 \pm 0.91 ), macular thickness(271.81 \pm 20 ), RNFL thickness(107.61 \pm 13$)$ and central corneal thickness(528.54 \pm 32 ) showed a strong positive correlation between the right eye and left along with no significant difference between male and female. Hence, only one eye was taken for further analysis.

In this study while running the ANOVA, we found no significant differences between the Average macular thicknesses [15] as found by Wong KS, Average RNFL thickness [25], Central Corneal Thickness [30,31] with age [16]. Except the axial length which shows a significant differences with specific age group 
with Group 1(15-25) compare to group 3(36-45) $\mathrm{P}=0.03$, and $4(46-55) \mathrm{P}=0.01$. Lastly, between group $5(>55)$ with group $1(15-25) \mathrm{P}=0.01$, by post HOC Bonferronoi.

The study proves, the data of all the parameters like Average macular thickness has a positive correlation (0.44) with Average RNFL $[6,20,35]$ and $P=0.00$. Axial length has a negative correlation with Age and Refractive status [26,28,30,31] (-0.30, and -0.56 respectively) with $\mathrm{P}=0.00$.

From this study, we are getting a closer look; apart from the parameters required, we can draw a conclusive action when doing a test that needs to be looked at. For age there is a positive correlation (0.38) with Refractive status $\mathrm{P}=0.00$, and negative correlation $(-0.18)$ to IOP $\mathrm{P}=0.02$. For Refractive status has negative correlation $(-0.16)$ with IOP $\mathrm{P}=0.05$. For IOP there is a negative correlation $(-0.18,-0.16)$ with Age and Refractive status respectively with $\mathrm{P}=0.05$, and positive correlation (0.17) with Axial length $P=0.03$. Lastly, Central corneal Thickness has positive correlation $(0.36)$ with IOP $\mathrm{P}=0.00$.

\section{Conclusion}

From all the parameters, they had a strong positive correlation between the right eye and left eye, with no significant difference between males and females. The parameters showed no significant relationship with age and refractive status. Except with the Axial, length has a significant difference with Age and Refractive status on specific age group.

IOP should take special consideration as they have significant relationship with Age, Refractive status, Central Corneal Thickness and Axial length. Knowledge and awareness of macular thickness and RNFL thickness, central corneal thickness and Axial length was given on Spectralis OCT in a normal NE population. In addition, it is important for the evaluation of pathological change in this ethnic group. Further studies is required to understand the association in all these parameters.

\section{Acknowledgement}

a) I would like to thank the divinity of God, who made it possible for me to complete this project.

b) A note of appreciation to Mr. Phani Krishna and Mr. Banshanhi Nongkhlaw. For their guidance, encouragement and enthusiasm during the period of my project work.

c) I also like to thank all the members of Mission Nethralaya Shillong who have inspired, helped and guided throughout this project.

d) I will be always indebted to my parents for their blessings and concern. It is my deep pleasure to acknowledge them.

\section{Conflict of Interest}

There is no conflict of interest in my study.

\section{References}

1. Md.Kayum Shikdar, Amit kumar Biswas, Ripon Mollick (2013) The socio economic background of khasia ethnic community of Bangladesh. IOSR journal of huminity and social science (IOSR JHSS) 7(4): 58-72.

2. Bulmenthal EZ, Weinreb RN (2001) Assessment of the retinal nerve fiber layer in clinical trails of glaucoma neuroprotection. Surv Ophthalmol 45(Suppl 3): S305-S312.

3. Xiaofei Chen, Chuang Nie, Yan Gong, Ying Zhang, Xin Jin, et al. (2015) Peripapillary retinal nerve fibre layer changes in preclinical diabetic retinopathy: a meta-analysis. PLoS ONE. 10(5): e0125919.

4. Demir M, Oba E, Sensoz H, Ozdal E (2014) Retinal nerve fiber layer and ganglion cell complex thickness in patients with type 2 diabetes mellitus. Indian J Ophthalmol 62(6): 719-720.

5. Gürses-Ozden R, Teng C, Vessani R, Zafar S, Liebmann JM, et al. (2004) Macular and retinal nerve fiber layer thickness measurement using Optical Coherence tomography. J Glaucoma 13(3): 238-244.

6. Huang J, Liu X, Wu Z, Guo X, Xu H, et al. (2011) Macular and retinal nerve fiber layer thickness measurement in normal with stratus OCT, HD- OCT, and Topcon 3D OCT. J Glaucoma 20(2): 118-125.

7. Schmid GF, Papastergiou GI, Nickla DL, Riva CE, Lin T (1996) Validation of laser Doppler interferometric measurement invivo of axial length and thickness of fundus layer in chicks. Curr Eye Res 15(6): 691-696.

8. R Forte, G L Cennamo, M L Finelli, G de Crecchio (2008) Comparison of time domain OCT and Spectral Domain SLO/OCT for assessment of macular thickness and volume. Nature 23: 2071-2078.

9. Pierro L, Zampedri E, Milani P, Gagliardi M, Isola V, et al. (2012) To compare the agreement between spectral domain optical coherence tomography (SD OCT) and time domain stratus OCT (TD OCT) in evaluating macular morphology alterations in wet age-related macular degeneration (AMD). Clin Ophthalmol 6: 219-223.

10. Schweitzer KD, Ehmann D, García R (2009) Nerve fibre layer changes in highly myopic eyes by optical coherence tomography. Can J Ophthalmol 44(3): e13-e16.

11. Budenz DL, Anderson DR, Varma R, Schuman J, Cantor L (2007) Determinants of Normal Retinal Nerve Fiber Layer Thickness Measured by Stratus OCT. Ophthalmology 114(6): 1046-1052.

12. Chan A, Duker JS, Ko TH, Fujimoto JG, Schuman JS (2006) Normal macular thickness measurements in healthy eyes using stratus optical coherence tomography. Arch Ophthalmol 124(2): 193-198.

13. Eriksson U, Alm A (2009) Macular thickness decrease with age in normal subjects: a study on the macular thickness map protocol in the Stratus OCT. Br J Ophthalmol 93(11): 1448-1452.

14. Mehreen Adhi, Sumbul Aziz, Kashif Muhammad, Mohammad I Adhi (2012) Macular thickness variations by age and gender in healthy eyes using the spectral domain optical coherence tomography. PLOS ONE 7(5): e37638.

15. Won Kyung Song, Sung Chul Lee, Eun Suk Lee, Chan Yun Kim, Sung Soo Kim (2010) Macular Thickness Variations with Sex, Age, and Axial Length in Healthy Subjects: A Spectral Domain-Optical Coherence Tomography Study. IOVS 2010. 51(8): 3913-3918.

16. Grover S, Murthy RK, Brar VS, Chalam KV (2009) Normative data for macular thickness by high-definition spectral-domain optical coherence tomography (spectralis). Am J Ophthalmol 148(2): 266-271.

17. Bindu Appukuttan, Anantharaman Giridhar, Mahesh Gopalakrishnan, Sobha Sivaprasad (2014) Normative spectral domain optical coherence tomography data on macular and retinal nerve fiber layer thickness in Indians. Indian J Ophthalmol 62(3): 316-321. 
18. Adhi M, Aziz S, Muhammad K, Adhi MI (2012) Macular Thickness by Age and Gender in Healthy Eyes Using Spectral Domain Optical Coherence Tomography. PLoS One 7(5): e37638.

19. Al-Zamil WM, Al-Zwaidi FM, Yassin SA (2017) Macular thickness in healthy Saudi adults a spectral-domain optical coherence tomography study. Saudi Med J 38(1): 63-69.

20. Aishwarya S, Manish Sharma, Kamlesh K (2016) A study of macular thickness, Retinal Nerve Fiber Layer thickness and Optic Nerve Head parameters in Healthy subjects using spectral Domain Optical Coherence Tomography. Journal of Dental and medical Science 15(6): 24-29.

21. Abhinav D, Renu D, RC Nagpal (2016) Correlation of Retinal Nerve fiber layer thickness and Axial Length on Fourier Domain OCT. J Clin Diagn Res 10(4): NC15-NC17.

22. Bindu Appukuttan, Anantharaman Giridhar, Mahesh Gopalakrishnan, Sobha Sivaprasad (2014) Normative spectral domain OCT on macular and retinal nerve fiber layer thickness in india. Indian J Ophthalmol 62(3); 316-321.

23. Kampougeris G, Spyropoulos D, Mitropoulou A, Zografou A, Kosmides P (2013) Peripapillary retinal nerve fibre layer thickness measurement with SD-OCT in normal and glaucomatous eyes: distribution and correlation with age. Int J Ophthalmol 6(5): 662-665.

24. Agarwal P, Saini VK, Gupta S, Sharma A (2014) Evaluation of central macular thickness and RNFL thickness using spectral domain OCT in tertiary Hospital. J Curr Glaucoma Pract 8(2): 75-81.

25. Fahmy RM (2017) Effect of refractive status and axial length on RNFL using OCT. Int J Ped \& Neo Heal 1(4): 91-95.

26. Dhami A, Dhasmana R, Nagpal RC (2016) To correlate the RNFL thickness and the axial length in normal individuals with Fourier domain Optical Coherence Tomography (OCT). J Clin Diagn Res 10(4): NC15-NC17.

27. Lameece MH, AF Shiaty, MM Salama, et al. (2015) To correlate macular thickness in the different degrees of myopia caused by increased axial length using Optical Coherence Tomography (OCT). Med J Cairo university, Volume 83.

28. Tobias Röck, Karl Ulrich Bartz-Schmidt, Matthias Bramkamp, Daniel Röck (2014) To assess the influence of axial length on spectral-domain optical coherence tomography (SD-OCT) thickness measurements in patients with subretinal visual implants. IVOS 55(11): 7494-7498.

29. Bhardwaj V, Rajeshbhai GP (2013) Axial Length, Anterior Chamber Depth-A Study in Different Age Groups and Refractive Errors. J Clin Diagn Res 7(10): 2211-2212.
30. Szigeti A, Tátrai E, Varga BE, Szamosi A, DeBuc DC, et al. (2015) To evaluate the effect of axial length (AL) on the thickness of intraretinal layers in the macula using optical coherence tomography (OCT) image analysis. PLoS ONE 10(11): e014238.

31. Lee JW, Yau GS, Woo TT, Lai JS (2015) The association between macular thickness and peripapillary retinal nerve fiber layer thickness in Chinese children. Medicine (Baltimore) 94(8): e567.

32. Kok PH, De Kinkelder R, Braaksma YC et al. (2013) To investigate the relationship between retinal thickness and axial length in amblyopic eyes compared to healthy eyes. J AAPOS 17(6): 598-602.

33. WK Song, SC Lee, ES Lee, et al. (2010) To assess the relationship between macular retinal thickness and volume and age, sex, and refractive error/axial length with spectral domain-optical coherence tomography (SD-OCT) 51: 3913-3918.

34. Yassin SA, Al-Tamimi ER (2016) Age, gender and refractive error association with intra ocular pressure in healthy Saudi participants. A cross sectional study. Saudi J Ophthalmol 30(1): 44-48.

35. Lee AJ, Saw SM, Gazzard G, Cheng A, Tan DT (2004) Intra ocular pressure association with refractive error and axial length. $\mathrm{Br} \mathrm{J}$ Ophthalmol 88(1): 5-7

36.Vijaya L, George R, Arvind H, Ve Ramesh S, Baskaran M, et al. (2010) Central corneal thickness in adult South Indians: the Chennai Glaucoma Study. Ophthalmology 117(4): 700-704.

37. Eghosasere Iyamu, Edoghogho Iyamu, Gabriel Amadasun (2012) Central corneal thickness and axial length in an adult Nigerian population. Journal of Optometry 6(3): 154-160.

38. Lederer DE, Schuman JS, Hertzmark E, Heltzer J, Velazques LJ, et al. (2003) Analysis of macular volume in normal and glaucomatous eyes using optical coherence tomography. Am J Ophthalmol 135(6): 838843 .

39. Ferdinand Rapthap, Wewe-u Khalo, Anton De Cruse Waanba, DeepaLamin Khonglah, Banshanhi I Nongkhlaw, et al. (2017) Validate the Correlation between Macular Thickness and Temporal Retinal Nerve Fiber Layer Thickness in Normal Eyes with Age and Refractive Status Using Stratus Optical Coherence Tomography. JOJ Ophthal 5(5): JOJO.MS.ID.555672.

40. Jonas JB, Budde WM, Panda-Jonas S (1999) Ophthalmoscopic evaluation of the optic nerve head. Surv Ophthalmol 43(4): 293-320.

\section{Your next submission with Juniper Publishers will reach you the below assets}

- Quality Editorial service

- Swift Peer Review

- Reprints availability

- E-prints Service

- Manuscript Podcast for convenient understanding

- Global attainment for your research

- Manuscript accessibility in different formats

( Pdf, E-pub, Full Text, Audio)

- Unceasing customer service

Track the below URL for one-step submission https://juniperpublishers.com/online-submission.php 